\title{
Open-label, clinical phase I studies of tasquinimod in patients with castration-resistant prostate cancer
}

\author{
O Bratt', M Häggman'², G Ahlgren ${ }^{3}$, Ö Nordle ${ }^{4}$, A Björk ${ }^{4}$ and J-E Damber ${ }^{*, 5}$ \\ 'Department of Urology, Helsingborg Hospital, Lund University, SE-25 187 Helsingborg, Sweden; ${ }^{2}$ Department of Urology, Uppsala University Hospital, \\ SE-75 85 Uppsala, Sweden; ${ }^{3}$ Department of Urology, Malmö University Hospital, UMAS, SE-20502 Malmö, Sweden; ${ }^{4}$ Active Biotech Research AB, \\ SE-22007 Lund, Sweden; ${ }^{5}$ Department of Urology, Bruna Stråket I I, Institute of Clinical Sciences, The Sahlgrenska Academy at University of Gothenburg, \\ SE-4 345 Gothenburg, Sweden
}

BACKGROUND: Tasquinimod is a quinoline-3-carboxamide derivative with anti-angiogenic activity. Two open-label phase I clinical trials in patients were conducted to evaluate the safety and tolerability of tasquinimod, with additional pharmacokinetic and efficacy assessments.

METHODS: Patients with castration-resistant prostate cancer with no previous chemotherapy were enrolled in this study. The patients received tasquinimod up to I year either at fixed doses of 0.5 or $1.0 \mathrm{mg}$ per day or at an initial dose of $0.25 \mathrm{mg}$ per day that escalated to $1.0 \mathrm{mg}$ per day.

RESULTS: A total of 32 patients were enrolled; 21 patients were maintained for $\geqslant 4$ months. The maximum tolerated dose was determined to be $0.5 \mathrm{mg}$ per day; but when using stepwise intra-patient dose escalation, a dose of $1.0 \mathrm{mg}$ per day was well tolerated. The dose-limiting toxicity was sinus tachycardia and asymptomatic elevation in amylase. Common treatment-emergent adverse events included transient laboratory abnormalities, anaemia, nausea, fatigue, myalgia and pain. A serum prostate-specific antigen (PSA) decline of $\geqslant 50 \%$ was noted in two patients. The median time to PSA progression ( $>25 \%$ ) was 19 weeks. Only 3 out of I5 patients (median time on study: 34 weeks) developed new bone lesions.

CONCLUSION: Long-term continuous oral administration of tasquinimod seems to be safe, and the overall efficacy results indicate that tasquinimod might delay disease progression.

British Journal of Cancer (2009) I 01, 1233- 1240. doi:I0.1038/sj.bjc.6605322 www.bjcancer.com

Published online 15 September 2009

(c) 2009 Cancer Research UK

Keywords: prostate cancer; tasquinimod; anti-angiogenesis; phase I study

In developed countries, prostate cancer is the second most frequently diagnosed cancer, and the third most common cause of death from cancer in men (Damber and Aus, 2008) with $\sim 240000$ new cases and $\sim 85000$ deaths a year from this cancer in Europe (Boyle and Ferlay, 2005). Metastatic disease is initially treated with androgen deprivation, which results in significant palliation for most patients (Huggins and Hodges, 1941; Denmeade and Isaacs, 2002). However, despite androgen deprivation and secondary hormonal manipulations, most patients eventually relapse on androgen ablative therapy and develop castrationresistant prostate cancer (CRPC). The median survival for patients with metastatic CRPC is $12-16$ months from the time of diagnosis to death (Heidenreich and Schrader, 2003). No curative treatments are available at this stage of the disease. To date, docetaxel-based regimens have shown a modest survival advantage (Petrylak et al, 2004; Tannock et al, 2004). A lack of cancer cell specificity limits both dose and total length of treatment with cytotoxic agents.

\footnotetext{
*Correspondence: Professor J-E Damber;

E-mail: jan-erik.damber@urology.gu.se

Received 27 May 2009; revised 18 August 2009; accepted 21 August 2009; published online 15 September 2009
}

Thus, there is a high medical need for novel and well-tolerated agents that delay disease progression.

After neovascularisation was identified as a prerequisite for growth and metastasis of solid tumours (Folkman, 1972), direct or indirect inhibition of angiogenesis has become a viable therapeutic approach in anti-cancer therapy. By the inhibition of tumour neovascularisation, tumour growth is suppressed. There is a significant correlation between the density of microvessels and the incidence of metastases in prostate cancer (Weidner et al, 1993). These observations make the angiogenic pathway a rationale target for directing therapies in prostate cancer and an attractive approach to new treatment options (Figg et al, 2002; Aragon-Ching and Dahut, 2008).

Tasquinimod (ABR-215050; CAS number: 254964-60-8) is a quinoline-3-carboxamide derivative inhibiting tumour angiogenesis (Isaacs et al, 2006; Dalrymple et al, 2007). Although the antiangiogenic mechanism of action of tasquinimod is presently unknown, it is not a vascular endothelial growth factor receptor (VEGFR) inhibitor. Pre-clinically, tasquinimod produced a robust inhibition of prostate cancer growth in vivo in a range of phenotypes and genotypes most characteristic of clinical tumours from patients with localised or metastatic, androgen receptor (AR)-positive or AR-negative, AR wild-type or mutant, as well as prostate-specific antigen (PSA)-positive or PSA-negative cancers. 
Treatment with a total daily dose of $1 \mathrm{mg} \mathrm{kg}^{-1}$ of tasquinimod over a period of 1 month decreased the tumour volume by at least $50 \%$ (Isaacs et al, 2006). This decrease in tumour volume was associated with a significant decrease in tumour blood vessel density. Similarly, the studies documented that a combination of androgen ablation or docetaxel with tasquinimod produced enhanced tumour growth retardation above that induced by either agent alone (Dalrymple et al, 2007).

In this study, we report the results of phase I studies in men with CRPC and PSA recurrence. The trials were conducted to define the safety and tolerability of tasquinimod when administered once daily and to serve as a basis for dose selection in future phase II studies. In addition, the studies investigated pharmacokinetics and the preliminary efficacy of tasquinimod.

\section{PATIENTS AND METHODS}

\section{Patients}

A total of 32 patients were enrolled for two multi-centre studies between February 2005 and January 2007. Eligibility criteria included informed consent, histologically or cytologically proven CRPC with PSA progression that was documented by at least two consecutive increases in PSA separated by at least 1 week during a maximum of 12 months before the initiation of therapy and a castrate level of testosterone $(<50 \mathrm{ng}$ per $100 \mathrm{ml})$ achieved by androgen-deprivation therapy through either surgical or pharmacological castration. Patients on a LHRH agonist were to continue androgen suppression during the studies. Patients who had received previous anti-androgen therapy were to have documented a subsequent increase in PSA after ceasing the anti-androgen. Patients were allowed on study without a detectable metastatic disease as assessed by bone scan or computed tomography (CT), provided they had documented increases in PSA. Patients had to have a score of 0 or 1 on the ECOG (Eastern Cooperative Oncology Group) performance status, and to have adequate bone marrow, renal and hepatic functions. Patients were excluded if they had clinical symptoms associated with prostate tumour progression, had received previous anti-cancer therapy (except for hormonal treatments), required systemic corticosteroids or warfarin, had previous significant cardiac events or had uncontrolled intercurrent illness. The use of strong CYP3A4 inhibitors or inducers was not permitted while on study because of potential drug interaction. The study was conducted in accordance with the Declaration of Helsinki, Good Clinical Practice Guidelines, ethical committee approval and applicable local laws and regulations.

\section{Study design}

The first of the two open-label studies conducted, study I, was a dose-escalation study to determine the maximum tolerated dose (MTD) of tasquinimod defined as the highest dose level at which no more than 1 out of 6 patients experienced a dose-limiting toxicity (DLT). Any drug-related grade 3 or 4 toxicity was considered a DLT. A cohort of six eligible patients was to receive an initial dose of $0.5 \mathrm{mg}$ orally once daily. If the patients tolerated this dose level, next cohorts, each comprising six patients, were to receive escalating doses (1.0, 2.0 and $3.0 \mathrm{mg}$ per day) of tasquinimod until the MTD was determined. The patients were to receive treatment with tasquinimod for 28 days, followed by a 1 -week off period, and during an extension study thereafter for up to 12 months (Figure 1). Dose escalation would stop if 2 DLTs were observed within a cohort, and the preceding cohort would be expanded with an additional 10 patients to allow greater precision for the estimates of toxicity.

The second study conducted, study II, was an intra-patient stepwise dose-escalation study in eight patients. The patients were to receive an initial dose of $0.25 \mathrm{mg}$ orally once daily for 3 weeks, and in the absence of treatment-related toxicity $0.5 \mathrm{mg}$ per day for another 3 weeks and finally $1.0 \mathrm{mg}$ per day for an additional 4 weeks. In the absence of treatment-related toxicity, patients were offered to continue their treatment at $1.0 \mathrm{mg}$ per day during an extension study for another 11 months.

According to study protocols, treatment was discontinued because of disease progression (investigator's decision), treatment-related toxicity or withdrawal of consent.

\section{Procedures}

In study I, patients were examined on days $1,5,8,15,23,28,35,49$, 63 and every 4 weeks thereafter until the final visit at 13 months. Safety evaluation was conducted at baseline and at each visit thereafter; that is, all patients underwent a physical examination, and vital signs, haematology, clinical chemistry, coagulation, urinalysis and ECG were evaluated. In addition, serum PSA values were measured at days $1,15,28,35$ and at every 4 weeks thereafter until the final visit. A PSA response was defined as a decrease in PSA $>50 \%$ from the baseline value and was confirmed by a second PSA value 4 weeks later (Bubley et al, 1999). The time to PSA progression was defined as the time from randomisation to a $\geqslant 25 \%$ increase in serum PSA from baseline or from on-treatment nadir PSA value (Scher et al, 2008). The PSA doubling time (PSADT) was calculated using the log-slope method (Daskivich et al, 2006). Regression analyses were conducted for the historic

Study I - Fixed dose

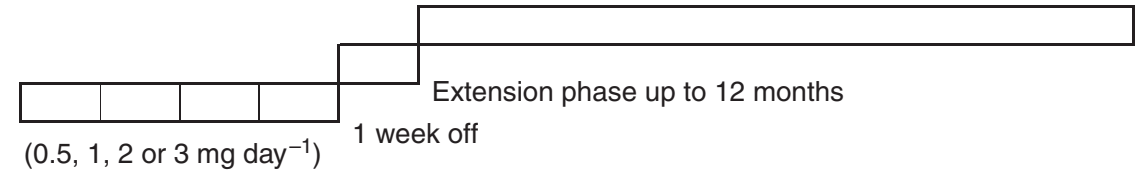

Study II - Intra-patient dose escalation



$\begin{array}{lllllllllllll}\text { Week } & 1 & 2 & 3 & 4 & 5 & 6 & 7 & 8 & 9 & 10 & 11 & 12\end{array}$

Figure I Study design of study I and study II. 
and on-study PSA data. Historic regression analysis was conducted using weighted linear regression. More weight was given to samples, which were closer to the screening visit. The weights were set at $1,0.5$ and 0.25 for values not older than weeks 16,32 and 52, respectively, before the first dose. Values older than week 52 before screening were excluded. In the on-study regression analysis, the same weight (weight $=1$ ) was given to all PSA values collected throughout the study.

Radiological imaging with bone scan was performed at screening and at every 2 months until the final visit. The overall time to PSA progression and radiographic progression was defined using Kaplan-Meier methods.

In study II, patients visited the study site on days $1,5,8,15,26$, $29,36,47,50,57,71$ and at 3 months and every 2 months thereafter until the final visit at 12 months. The procedure for safety evaluation was the same as in study I. PSA measurements were performed at baseline, on day 71 and every 2 months thereafter.

In study I, extensive pharmacokinetic sampling was performed on days 1 and 28. Besides, a blood sample (pre-dose) was collected at all visits. Tasquinimod concentrations in plasma samples were determined using a validated liquid chromatography mass spectrometry/mass spectrometry method. Briefly, the plasma sample was prepared for injection onto the column by protein precipitation, followed by centrifugation. Quantitation was based on stable isotope dilution. The workable concentration range for the method was $1-2500 \mathrm{nmoll}^{-1}$ with inter-batch precision and accuracy in the same concentration interval being 6.1 and $102.9 \%$, respectively. Pharmacokinetic parameters, including area under the concentration-time curve (AUC), maximum concentration $\left(\mathrm{C}_{\max }\right)$, time to $\mathrm{C}_{\max }\left(t_{\max }\right)$ and elimination half-life $\left(t_{1 / 2}\right)$ were evaluated by non-compartmental analysis using WinNonlin professional software version 5.0.1 (Pharsight Corp., Mountain View, CA, USA).

\section{Statistical evaluations}

All variables are presented using descriptive statistics. No formal statistical tests were conducted in these studies.

\section{RESULTS}

\section{Patient characteristics}

In total, 32 patients were enrolled for these studies. Baseline clinical and biological characteristics are described in Table 1. Patients ranged in age from 46 to 82 years, and all of them were Caucasian. There were no clinically meaningful differences between the patients in baseline characteristics in the two studies, including factors with established prognostic importance in prostate cancer (Smaletz et al, 2002; Armstrong et al, 2007). The median PSA concentration at study entry was $19 \mathrm{ng} \mathrm{ml}^{-1}$ (range: 2.6-1400). Pre-treatment median PSADT was 25 weeks (range: 8 to $>999$ ). Two patients had a decline in PSA just before entering the study, in one patient after discontinuing anti-androgen treatment. Bone scan was performed in study I, and $50 \%$ of the patients had bone metastatic disease at baseline.

\section{Efficacy}

Two patients in the $0.5 \mathrm{mg}$ dose group in study I had a PSA decline of $>50 \%$ at 10 and 26 weeks, lasting for $>7$ and 13 weeks, respectively. An additional patient had a decline of $>30 \%$ at 9 weeks lasting for 12 weeks. The best PSA response in all patients treated for $>15$ days $(n=28)$ are graphically shown in the waterfall chart in Figure 2. The estimated proportion of patients without PSA progression at week 18 was $56 \%$. The median PSA progression-free time was 19 weeks (95\% CI, $13-25$ weeks; $n=23$ ) in patients entering the extension phase (Figure 3 ). The median
Table I Baseline characteristics

\begin{tabular}{|c|c|c|c|}
\hline \multirow[b]{2}{*}{ Variable } & \multicolumn{2}{|c|}{ Study $I^{\mathrm{a}}(n=24)$} & \multirow[b]{2}{*}{$\begin{array}{c}\text { Study II' } \\
(n=8)\end{array}$} \\
\hline & $\begin{array}{c}0.5 \text { mg per day } \\
(n=17)\end{array}$ & $\begin{array}{c}1.0 \mathrm{mg} \text { per day } \\
(n=7)\end{array}$ & \\
\hline \multicolumn{4}{|l|}{ Age, years } \\
\hline Median & 72 & 77 & 73 \\
\hline Range & $46-82$ & $58-82$ & $61-78$ \\
\hline \multicolumn{4}{|c|}{ PSA, ng per $100 \mathrm{ml}$} \\
\hline Median & 19 & 112 & 9.4 \\
\hline Range & $2.6-1400$ & $6.3-1188$ & $5.0-25$ \\
\hline \multicolumn{4}{|l|}{ PSADT, weeks } \\
\hline Median & 23 & 27 & 29 \\
\hline Range & 8 to $>999$ & $|3-8|$ & 9 to $>999$ \\
\hline \multicolumn{4}{|l|}{ Gleason's score } \\
\hline Median & 7 & 7 & 7 \\
\hline Range & $6-9$ & $6-10$ & $6-9$ \\
\hline \multicolumn{4}{|l|}{ Gleason's score, n } \\
\hline$\leqslant 6$ & | (6\%) & | (I4\%) & | (13\%) \\
\hline 7 & $6(35 \%)$ & $2(29 \%)$ & $3(38 \%)$ \\
\hline $8-10$ & $6(35 \%)$ & $2(29 \%)$ & $2(25 \%)$ \\
\hline Indeterminate & $4(24 \%)$ & $2(29 \%)$ & $2(25 \%)$ \\
\hline \multicolumn{4}{|l|}{ Bone metastases $^{c}$} \\
\hline MO & $8(47 \%)$ & $4(57 \%)$ & $3(38 \%)$ \\
\hline $\mathrm{MI}$ & $9(53 \%)$ & $3(43 \%)$ & $3(38 \%)$ \\
\hline$M X$ & 0 & 0 & $2(25 \%)$ \\
\hline \multicolumn{4}{|l|}{ ECOG, $n$} \\
\hline 0 & $17(100 \%)$ & $6(86 \%)$ & 7 (88\%) \\
\hline । & 0 & I (14\%) & 0 \\
\hline Indeterminate & 0 & 0 & I (I3\%) \\
\hline \multicolumn{4}{|l|}{ Haemoglobin, $g l^{-1}$} \\
\hline Median & 142 & 127 & 133 \\
\hline Range & $124-154$ & $107-140$ & $126-148$ \\
\hline \multicolumn{4}{|c|}{ Alkaline phosphatase, $\mu k a t I^{-1}$} \\
\hline Median & 1.2 & 1.5 & 1.6 \\
\hline Range & $0.8-10$ & $0.7-3.2$ & $0.9-2.1$ \\
\hline \multicolumn{4}{|c|}{ Lactate dehydrogenase, $\mu \mathrm{kat} I^{-1}$} \\
\hline Median & 3.5 & 3.7 & 2.9 \\
\hline Range & $2.1-5.7$ & $3.1-4.3$ & $2.2-3.5$ \\
\hline
\end{tabular}

Abbreviations: $\mathrm{ECOG}=$ Eastern Cooperative Oncology Group; PSA = prostatespecific antigen; PSADT = prostate-specific antigen doubling time. ${ }^{\text {a } F i x e d ~ d o s e ~}$ groups. ${ }^{b}$ Intra-patient dose-escalation group. ${ }^{\mathrm{C}} \mathrm{No}$ soft tissue lesions were observed.

pre-treatment PSADT was 25 weeks, and the median PSADT at 18 weeks was 65 weeks. In all, 18 patients had prolonged PSADT while on study; in 5 patients PSADT was shortened.

Bone scans were performed at baseline and thereafter at every 2 months in the fixed $0.5 \mathrm{mg}$ dose group. In all, 7 (47\%) out of 15 patients continuing during the extension study had positive scans at baseline. It is noteworthy that there was no finding of bone scan progression at the end of study in $12(80 \%)$ patients (median treatment time: 34 weeks; range: 15-54) (Figure 4). One (14\%) patient with a positive scan at baseline developed new lesions at week 53; two (25\%) patients with negative scans at baseline developed new bone lesions at weeks 13 and 21, respectively. No patient in the trial developed tumour-related pain requiring treatment with opioid drugs. The median time to PSA progression for patients with and without bone lesions at baseline was $9(95 \%$ CI, 5 - 23 weeks; $n=7$ ) and 23 weeks (95\% CI, 13 - 56 weeks; $n=8$ ), 


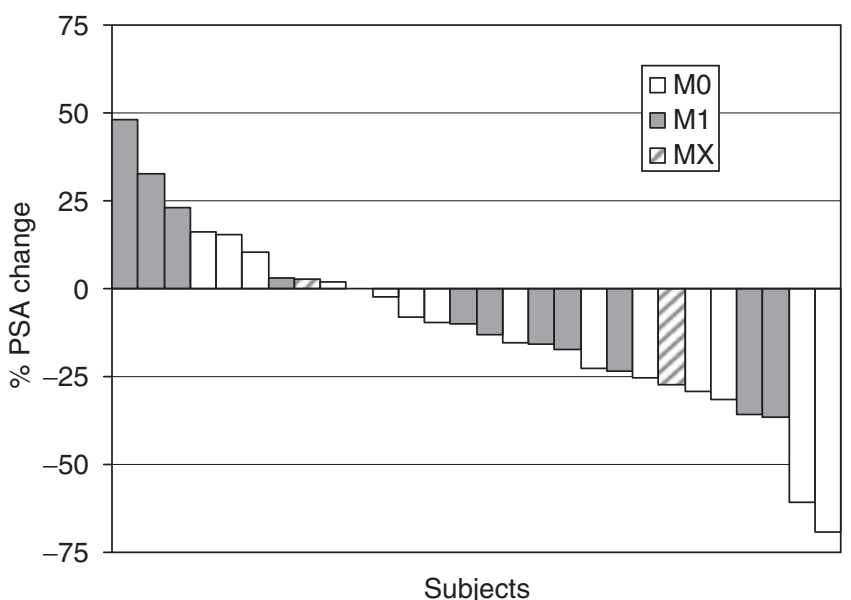

Figure 2 Waterfall plot of best PSA response per subject, with each bar representing one patient's lowest percentage decline after treatment initiation $(n=28)$. The 28 patients are divided into three groups (MO, MI, and $M X)$ according to distant metastasis on bone scan at baseline.

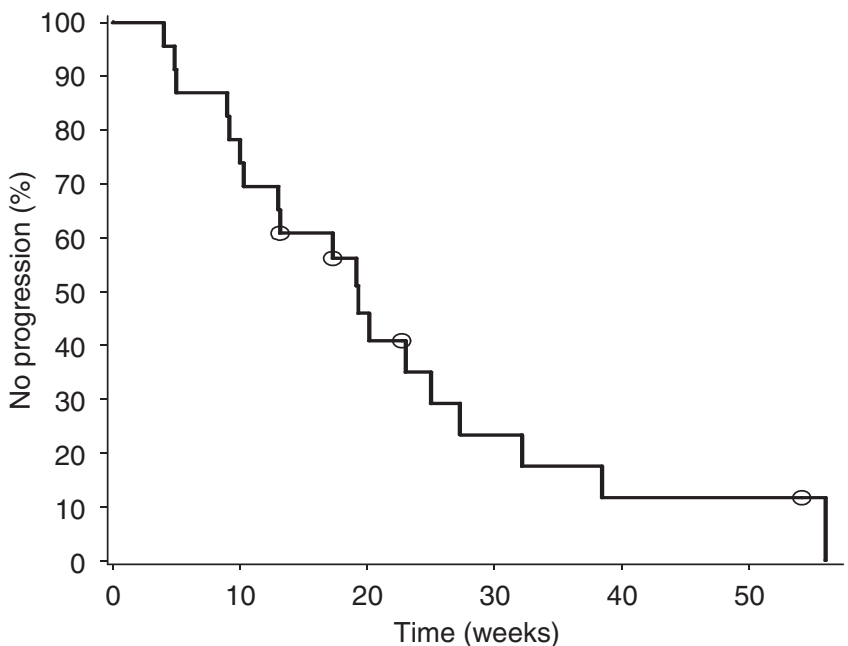

Figure 3 Kaplan-Meier graph of time to PSA progression (PSA increase $>25 \%$ over baseline or on-treatment NADIR) in patients entering the extension phase $(n=23$; censored subjects $=$ circle). The median PSA PFS was 19 weeks.

respectively. All three patients who developed new bone lesions also progressed by PSA criteria.

Notably, patients treated with tasquinimod responded with a decrease in serum lactate dehydrogenase (LDH) levels. Compared with baseline, patients had a LDH mean ( \pm s.e.m.) decrease of $20 \pm 3 \%$ at 4 months.

\section{Maximum tolerated dose}

In study I, 24 patients received tasquinimod at fixed doses of 0.5 (17 patients) or $1.0 \mathrm{mg}$ (7 patients) orally once daily on a continuous dosing schedule for 28 days. Patients treated at the $0.5 \mathrm{mg}$ dose level tolerated the therapy without DLT. In the cohort comprising seven patients at a dose level of $1.0 \mathrm{mg}$ per day, two patients experienced DLT as pre-defined by protocol (Table 2). One patient had an asymptomatic CTC grade 3 elevation in amylase on day 23 . He recovered without any clinical intervention within 2 weeks. The second DLT patient had chest and back pain

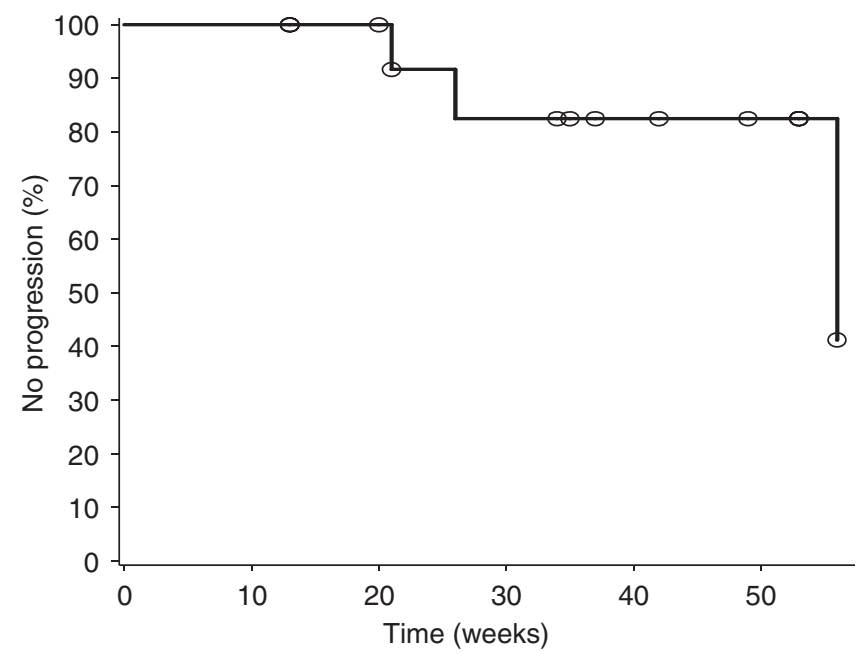

Figure 4 Kaplan-Meier graph of time to new bone lesions in patients treated at a fixed dose of $0.5 \mathrm{mg}$ per day $(n=15$; censored subjects $=$ circle)

Table 2 No. of patients with tasquinimod related CTC grade 3 adverse events/SAE/DLT

\begin{tabular}{|c|c|c|c|c|}
\hline & $\begin{array}{c}\text { Dose level mg } \\
\text { per day }\end{array}$ & $\begin{array}{c}\text { No. of } \\
\text { patients }\end{array}$ & SAE & DLT \\
\hline \multicolumn{5}{|l|}{ Study 1} \\
\hline Back pain & 0.5 & I & & \\
\hline \multirow[t]{2}{*}{ Hyperamylasaemia } & 0.5 & 2 & & \\
\hline & 1.0 & I & & I \\
\hline Sinus tachycardia & 1.0 & i & । & i \\
\hline \multicolumn{5}{|l|}{ Study \| } \\
\hline Cerebral infarction & 1.0 & । & । & \\
\hline Chest pain & 1.0 & i & $1^{a}$ & \\
\hline
\end{tabular}

Abbreviation: DLT = dose-limiting toxicity. ${ }^{\text {aT }}$ This patient also experienced another Serious Adverse Event (SAE), musculoskeletal pain Common Toxicity Criteria (CTC) grade 2 .

and was hospitalised on day 10 because of a grade 3 cardiac arrhythmia. The patient had periods of supraventricular tachycardia. There were no signs consistent with myocardial infarction. He received treatment with $\beta$-blockers and recovered 2 weeks later. Owing to these events, the remaining patients in the $1.0 \mathrm{mg}$ dose group were discontinued prematurely. The MTD of tasquinimod was determined to be $0.5 \mathrm{mg}$ once daily.

The $0.5 \mathrm{mg}$ dose group was expanded with an additional 11 patients. All patients in the $0.5 \mathrm{mg}$ dose group completed the 28-day treatment period. After 1-week of treatment, patients without signs of tumour progression were offered to continue tasquinimod treatment for up to 12 months. In all, 15 (88\%) out of the 17 patients entered the extension phase. The mean number of days with intake of study drug in the 0.5 and $1.0 \mathrm{mg}$ dose groups was 240 and 11, respectively. Three (20\%) patients completed the 12-month extension study.

\section{Safety results}

Inflammation (41\%) was the most common adverse event associated with tasquinimod in the fixed $0.5 \mathrm{mg}$ dose group during the first 4 weeks of treatment (Table 3). In this study, inflammation is defined as increased levels of laboratory markers, constituting laboratory changes above the upper limit normal not associated with clinical symptoms requiring any clinical intervention. In the 
Table 3 Percentage of patients with tasquinimod-related adverse events (only symptoms occurring in two or more patients $(n=32)$ )

\begin{tabular}{|c|c|c|c|c|c|c|c|c|c|}
\hline \multirow[b]{2}{*}{ soc } & \multirow[b]{2}{*}{$\begin{array}{l}\text { Dictionary- } \\
\text { derived term }\end{array}$} & \multicolumn{2}{|c|}{$\begin{array}{l}\text { Fixed } 0.5 \mathrm{mg} \text { per } \\
\text { day }(n=17)\end{array}$} & \multicolumn{2}{|c|}{$\begin{array}{l}\text { Fixed } 1.0 \mathrm{mg} \\
\text { per day }(n=7)\end{array}$} & \multicolumn{2}{|c|}{$\begin{array}{l}\text { Fixed } 0.5 \mathrm{mg} \text { per day } \\
\text { extension }(n=15)\end{array}$} & \multicolumn{2}{|c|}{$\begin{array}{c}0.25-1.0 \mathrm{mg} \\
\text { per day }(n=8)\end{array}$} \\
\hline & & $\begin{array}{l}\text { Grades } \\
\text { I and } 2(\%)\end{array}$ & $\begin{array}{l}\text { Grade } \\
3(\%)\end{array}$ & $\begin{array}{l}\text { Grades } \\
\text { I and } 2(\%)\end{array}$ & $\begin{array}{l}\text { Grade } \\
3(\%)\end{array}$ & $\begin{array}{l}\text { Grades } \\
\text { I and } 2(\%)\end{array}$ & $\begin{array}{l}\text { Grade } \\
3(\%)\end{array}$ & $\begin{array}{l}\text { Grades } \\
\mathrm{I} \text { and } 2(\%)\end{array}$ & $\begin{array}{l}\text { Grade } \\
3 \text { (\%) }\end{array}$ \\
\hline $\begin{array}{l}\text { Blood and lymphatic system } \\
\text { disorders }\end{array}$ & Anaemia & 18 & & 29 & & 33 & & & \\
\hline Gastrointestinal disorders & Abdominal pain & 12 & & & & & & & \\
\hline \multirow{5}{*}{$\begin{array}{l}\text { General disorders and } \\
\text { administration site conditions }\end{array}$} & Fatigue & 18 & & 43 & & 7 & & 13 & \\
\hline & Feeling cold & 6 & & 29 & & & & & \\
\hline & Inflammation & 41 & & 29 & & 33 & & & \\
\hline & Pain & 12 & & & & & & & \\
\hline & Pyrexia & 6 & & & & & & 13 & \\
\hline \multirow[t]{5}{*}{ Investigations } & $\begin{array}{l}\text { Blood fibrinogen } \\
\text { increased }\end{array}$ & 24 & & & & 7 & & & \\
\hline & $\begin{array}{l}\text { Neutrophil count } \\
\text { increased }\end{array}$ & 12 & & & & 7 & & & \\
\hline & $\begin{array}{l}\text { Platelet count } \\
\text { increased }\end{array}$ & 6 & & & & 13 & & & \\
\hline & ESR increased & 18 & & & & 7 & & & \\
\hline & $\begin{array}{l}\text { WBC count } \\
\text { increased }\end{array}$ & 24 & & & & 7 & & & \\
\hline \multirow{2}{*}{$\begin{array}{l}\text { Metabolism and nutrition } \\
\text { disorders }\end{array}$} & Hyperamylasaemia & & 12 & & 14 & 7 & & & \\
\hline & Hypercalcaemia & 6 & & 14 & & & & & \\
\hline \multirow{2}{*}{$\begin{array}{l}\text { Musculoskeletal and connective } \\
\text { tissue disorders }\end{array}$} & Arthralgia & & & 14 & & & & 13 & \\
\hline & Muscular weakness & 6 & & & & 7 & & & \\
\hline
\end{tabular}

Abbreviations: $\mathrm{Hb}=$ haemoglobin; $\mathrm{WBC}=$ white blood cell; $\mathrm{CRP}=\mathrm{C}$-reactive protein; $\mathrm{ESR}=$ erythrocyte sedimentation rate; $\mathrm{SOC}=$ system organ class.

fixed $1.0 \mathrm{mg}$ dose group, nausea (57\%) and fatigue (43\%) were the most common adverse events. The majority of these events was CTC grade 1 in severity, transient and occurred early after the start of treatment.

The most commonly occurring adverse events assessed as related to tasquinimod in the intra-patient dose-escalation study (study II) were myalgia (25\%), hypoesthesia (25\%) and pain in extremity $(25 \%)$.

Compared with baseline, patients in both study I and study II had mean haemoglobin decreases of 12 and $16 \mathrm{gl}^{-1}$, respectively. These changes occurred within 2 weeks of the initiation of treatment and were stabilised 6 weeks later, except for one case of anaemia for which a blood transfusion was required.

In the fixed $0.5 \mathrm{mg}$ dose group, there were decreases in mean systolic and diastolic blood pressure levels starting during the first weeks of treatment continuing throughout the study. At 3 months, the mean ( \pm s.e.m.) systolic blood pressure was decreased by $20.6 \pm 5.3 \mathrm{mmHg}$ and the diastolic blood pressure by $5.3 \pm 2.4 \mathrm{mmHg}$. At 10 weeks in the intra-patient dose-escalation study, there was also a similar decrease in mean ( \pm s.e.m.) systolic and diastolic blood pressure levels, that is, $18.1 \pm 6.4$ and $7.4 \pm 2.0 \mathrm{mmHg}$, respectively. No other changes in vital signs (mean pulse, mean oral body temperature, mean body weight) or ECG parameters were considered clinically relevant.

In study I, five patients experiencing severe adverse events (CTC grade 3) were documented (Table 3). No adverse event of CTC grade 4 was observed. Two patients in the $0.5 \mathrm{mg}$ dose group developed asymptomatic CTC grade 3 elevations in amylase on day 8. These abnormalities resolved without treatment interruption and were normalised within 7 days. A third patient experienced back pain. He recovered with sequelae in one day. The two patients who experienced DLT are described above.

In study II, three SAEs were recorded in two patients during the study in which a causal relationship with tasquinimod could not be excluded. One patient experienced two SAEs, namely musculoskeletal pain (CTC grade 2) and chest pain (CTC grade 3). The patient discontinued the study because of the pain and recovered. Another patient experienced an SAE of cerebral infarction (CTC grade 3). Approximately 1 year after starting to take the study drug, this patient noted aphasia and poor coordination of his left body half and was hospitalised. A CT scan of the brain showed no pathological changes. He received treatment with enalapril, acetylsalicylic acid and simvastain. The patient recovered and was discharged from the hospital 3 days later. 


\section{Plasma PK}

In the $0.5 \mathrm{mg}$ fixed dose group, the maximum plasma concentration $\left(\mathrm{C}_{\max }\right)$ (mean: $0.26 \mu \mathrm{moll}^{-1}, n=17$ ), was attained at $2.6 \mathrm{~h}$. The oral clearance $(\mathrm{CL} / \mathrm{F})$ was $0.28 \mathrm{lh}^{-1}$ (mean) and the oral volume of distribution (V/F) was 151 (mean), resulting in an elimination halflife of $40 \pm 16 \mathrm{~h}$ (mean \pm s.d.). The AUC at steady state amounted to $4.8 \mu \mathrm{mol} \mathrm{hl}^{-1}$ (mean). The accumulation ratio in plasma level $\left(\mathrm{AUC}_{24 \mathrm{~h}}\right.$ ) by multiple dosing was 2.8 and was expected on the basis of the half-life of tasquinimod. The steady-state plasma concentrations of tasquinimod showed no time dependency in the exposure during up to 1 year of treatment: the state pre-dose (trough) concentration of tasquinimod (mean: $0.19 \mu \mathrm{moll}^{-1}$ ) determined during 12 months of daily administration was the same as after 14 days of administration. The pharmacokinetic properties were not affected by food intake. The pre-dose plasma concentrations of tasquinimod determined after 14 days of daily administration at $0.25,0.5$ and $1.0 \mathrm{mg}$ in the intra-patient dose-escalation study were $0.13 \pm 0.02,0.23 \pm 0.03$ and $0.42 \pm 0.05 \mu \mathrm{moll}^{-1}$ (mean \pm s.e.m., $n=8$ ), respectively. No essential dose dependency of the pharmacokinetics was observed.

\section{DISCUSSION}

Structurally, tasquinimod is related to roquinimex (linomide), which was tested in a series of phase II and III trials in patients with advanced renal cell carcinoma (de Wit et al, 1997; Pawinski et al, 1997) and in those with multiple sclerosis (MS) (Noseworthy et al, 2000). In patients with renal cell cancer, the efficacy was modest with influenza-like symptoms of myalgia, arthralgia and fatigue being the most common adverse events. Roquinimex was terminated because of unanticipated serious cardiopulmonary toxicities detected in studies on MS patients. The mechanism of these adverse effects is unknown, but may be related to a proinflammatory reaction seen in a polyarthritis model mimicking proinflammatory side effects in the dog. Doses of roquinimex that inhibit tumour growth in the mouse induce a proinflammatory reaction in the dog. Its main characteristics are fever, neutrophilia and an increase in acute-phase reactant levels (Jönsson et al, 2004). When the toxicity of tasquinimod was assessed in dogs, only occasional increases in acute-phase reactants and white blood cell counts were observed (unpublished observation), and hence inducing systemic inflammatory reactions seems to have less significance for tasquinimod. Pre-clinically, tasquinimod is $30-60$ times more potent than roquinimex in its anti-tumour efficacy (Isaacs et al, 2006). Thus, compared with roquinimex, significant improvements in both anti-angiogenic and anti-prostate cancer activities and safety aspects have been accomplished in tasquinimod.

On the basis of the effects of tasquinimod against human prostate cancer xenografts, it has entered clinical development as therapy for prostate cancer. These phase I trials were conducted to evaluate the safety and preliminary efficacy of tasquinimod in men with asymptomatic CRPC without previous systemic chemotherapy.

In these phase I studies, tasquinimod could be safely administered at $0.5-1.0 \mathrm{mg}$ per day during long-term treatment. Most adverse events occurred within the first 4 weeks of treatment. Of a total of 71 related adverse events in the fixed $0.5 \mathrm{mg}$ dose group, $76 \%$ were recorded until day 35. Raised inflammatory markers not associated with clinical symptoms are the most frequent adverse effects, whereas fatigue, myalgia and nausea are the most common symptomatic adverse events. Nausea seemed to be related to taking tasquinimod under fasting conditions.

On the basis of the observations that most laboratory changes were transient, not associated with clinical symptoms and occurred early after the start of treatment, an intra-patient stepwise dose- escalation study was conducted to determine whether these laboratory changes could be reduced. Given the small sample size in the intra-patient dose-escalation group, it is not possible to provide a precise estimate, but the intra-patient dose-escalation regimen seemed to decrease the number of related adverse events per patient per month. Thus, the intra-patient doseescalation regimen may prove beneficial to future trials with tasquinimod.

Several patients developed asymptomatic elevations in amylase $\sim 1$ week after the start of treatment. Amylase levels normalised without dose interruption within a couple of weeks. The reasons for this transient elevation in amylase are unknown. As hyperamylasaemia was not associated with clinical symptoms and no patient developed acute pancreatitis, it is possible that the asymptomatic increase in amylase should not be considered as a relevant DLT. Notably, asymptomatic increases in serum levels of amylase and lipase have been observed with the antiangiogenic agents such as sorafenib, sunitinib, and temsirolimus and may represent a class effect (Escudier et al, 2006; Bhojani et al, 2008). However, other side effects noted with VEGFR inhibitors and agents targeting VEGF such as skin rashes, hand-foot skin reactions, diarrhoea, hypertension and neuropathic changes (Kane et al, 2006; Rock et al, 2007) were not observed with tasquinimod. Thus, there seems to be a substantial difference in the side effect profile of tasquinimod compared with VEGFR inhibitors.

Several anti-angiogenic therapies are currently under intense clinical investigation both as stand-alone therapies and as adjuvants to chemotherapy to enhance the anti-tumour activity of the latter. In general, the PSA response of the anti-angiogenic agents as stand-alone therapies in metastatic androgen-independent prostate cancer is modest (Figg et al, 2001; Reese et al, 2001; Steinbild et al, 2007; Dahut et al, 2008).

The present trials were primarily designed to evaluate the safety of tasquinimod. However, efficacy was addressed by measuring PSA levels in all patients and by bone scan in patients treated at $0.5 \mathrm{mg}$ per day. Preclinical data suggest that the effect of tasquinimod on serum PSA levels is related to its inhibitory effect on tumour growth (Dalrymple et al, 2007), which supports a hypothesis that a clinical change in PSA slope or PSADT is indicative of a therapeutic response to tasquinimod. In the current studies, $56 \%$ of patients were progression free by PSA criteria ( $<25 \%$ increase) at 18 weeks. The median PSADT up to 18 weeks was 65 weeks compared with the median pre-treatment PSADT of 25 weeks. In this respect, tasquinimod as a stand-alone therapy seems to be superior to most other anti-angiogenic agents both in terms of PSA progression-free survival and PSA declines. Repeated radiological imaging with bone scan was performed in patients who received the fixed dose of $0.5 \mathrm{mg}$ per day. Seven of these patients had a positive bone scan at baseline, whereas eight patients had negative scans. Only three $(20 \%)$ patients had radiographic progression on bone scans. Two of these patients had negative bone scans at baseline. No patient had evidence of tumour-related pain. However, this study did not conform to the recent recommendation of the PCWG2 (Prostate Cancer Clinical Trials Working Group) to assess the progression on bone scan (Scher et al, 2008). Therefore, it is important that future studies be harmonised with these novel recommendations. Two patients had PSA progression (at 5 and 9 weeks, respectively) before radiographic progression (at 53 and 13 weeks, respectively), and one patient had PSA and radiographic progression at the same time (at 21 weeks). Two of these patients had negative bone scans at baseline. No patient had evidence of tumour-related pain.

Lactate dehydrogenase levels may be a marker for tumour burden (Smaletz et al, 2002; George et al, 2005). It was observed that patients experienced a decrease in their LDH levels during treatment. Interestingly, LDH levels are not affected in healthy 
subjects treated with tasquinimod (data not shown). Alkaline phosphatase levels were only affected to a minor extent.

In conclusion, there is a need for novel therapies for treating metastatic prostate cancer. Anti-angiogenic therapy has demonstrated its potential as a therapy to stabilise or delay disease progression. Although caution must be exercised in interpreting early data, treatment in the form of long-term continuous oral administration of tasquinimod seems to be safe and well tolerated with a favourable pharmacokinetic profile, and overall efficacy results indicate that tasquinimod might delay disease progression. On the basis of the encouraging phase I results, a randomised phase II program is currently being performed to further determine the efficacy and safety of tasquinimod in asymptomatic patients with metastatic CRPC. The tasquinimod profile demonstrated may also prove beneficial to future trials combining tasquinimod with chemotherapy, radiation, anti-hormonal or other anti-angiogenic agents.

\section{ACKNOWLEDGEMENTS}

We acknowledge the assistance of the following people in the initial design and conduct of the studies: Suzanne Kilany and Karin Hannander. This work was financially supported by Active Biotech Research $\mathrm{AB}$ in their role as sponsor. Orjan Nordle and Anders Björk are employees of Active Biotech Research AB.

\section{Conflict of interest}

The authors declare no conflict of interest.

\section{REFERENCES}

Aragon-Ching JB, Dahut WL (2008) The role of angiogenesis inhibitors in prostate cancer. Cancer J 14: $20-25$

Armstrong AJ, Garrett-Mayer ES, Yang YC, de Wit R, Tannock IF, Eisenberger M (2007) A contemporary prognostic nomogram for men with hormone-refractory metastatic prostate cancer: a TAX327 study analysis. Clin Cancer Res 13: 6396-6403

Bhojani N, Jeldres C, Patard JJ, Perrotte P, Suardi N, Hutterer G, Patenaude F, Oudard S, Karakiewicz PI (2008) Toxicities associated with the administration of sorafenib, sunitinib, and temsirolimus and their management in patients with metastatic renal cell carcinoma. Eur Urol 53: $917-930$

Boyle P, Ferlay J (2005) Cancer incidence and mortality in Europe, 2004. Ann Oncol 16: $481-488$

Bubley GJ, Carducci M, Dahut W, Dawson N, Daliani D, Eisenberger M, Figg WD, Freidlin B, Halabi S, Hudes G, Hussain M, Kaplan R, Myers C, Oh W, Petrylak DP, Reed E, Roth B, Sartor O, Scher H, Simons J, Sinibaldi V, Small EJ, Smith MR, Trump DL, Vollmer R, Wilding G (1999) Eligibility and response guidelines for phase II clinical trials in androgen-independent prostate cancer: recommendations from the Prostate-Specific Antigen Working Group. J Clin Oncol 17: $3461-3467$

Dahut WL, Scripture C, Posadas E, Jain L, Gulley JL, Arlen PM, Wright JJ, Yu Y, Cao L, Steinberg SM, AragonChing JB, Venitz J, Jones E, Chen CC, Figg WD (2008) A phase II clinical trial of sorafenib in androgenindependent prostate cancer. Clin Cancer Res 14: 209-214

Dalrymple SL, Becker RE, Isaacs JT (2007) The quinoline-3-carboxamide anti-angiogenic agent, tasquinimod, enhances the anti-prostate cancer efficacy of androgen ablation and taxotere without effecting serum PSA directly in human xenografts. Prostate 67: 790-797

Damber JE, Aus G (2008) Prostate cancer. Lancet 371: 1710-1721

Daskivich TJ, Regan MM, Oh WK (2006) Prostate specific antigen doubling time calculation: not as easy as 1, 2, 4. J Urol 176: 1927-1937

de Wit R, Pawinsky A, Stoter G, van Oosterom AT, Fosså SD, Paridaens R, Svedberg A, de Mulder PH (1997) EORTC phase II study of daily oral linomide in metastatic renal cell carcinoma patients with good prognostic factors. Eur J Cancer 33: 493-495

Denmeade S, Isaacs JT (2002) A history of prostate cancer treatment. Nat Rev Cancer 2: $389-396$

Escudier B, Szczylik C, Eisen T, Oudard S, Stadler WM, Schwartz B, Shan M, Bukowski RM (2006) Randomized phase III trial of the multikinase inhibitor sorafenib (BAY 43-9006) in patients with advanced renal cell carcinoma (RCC). Eur Urol Suppl 5: 287

Figg WD, Dahut W, Duray P, Hamilton M, Tompkins A, Steinberg SM, Jones E, Premkumar A, Linehan WM, Floeter MK, Chen CC, Dixon S, Kohler DR, Krüger EA, Gubish E, Pluda JM, Reed E (2001) A randomized phase II trial of thalidomide, an angiogenesis inhibitor, in patients with androgen-independent prostate cancer. Clin Cancer Res 7: 1888-1893

Figg WD, Kruger EA, Price DK, Kim S, Dahut WD (2002) Inhibition of angiogenesis: treatment options for patients with metastatic prostate cancer. Invest New Drugs 20: $183-194$

Folkman J (1972) Anti-angiogenesis: new concept for therapy of solid tumors. Ann Surg 175: 409-416
George DJ, Halabi S, Shepard TF, Sanford B, Vogelzang NJ, Small EJ, Kantoff PW (2005) The prognostic significance of plasma interleukin-6 levels in patients with metastatic hormone-refractory prostate cancer: results from cancer and leukemia group B 9480. Clin Cancer Res 11: $1815-1820$

Heidenreich A, Schrader AJ (2003) The treatment of hormone refractory prostate cancer. EAU Update Series 1: $40-50$

Huggins CB, Hodges CV (1941) Studies on prostatic cancer: I. The effect of castration, of estrogen and of androgen injection on serum phosphatases in metastatic carcinoma of the prostate. Cancer Res 1: $293-297$

Isaacs JT, Pili R, Qian DZ, Dalrymple SL, Garrison JB, Kyprianou N, Björk A, Olsson A, Leanderson T (2006) Identification of ABR-215050 as lead second generation quinoline-3-carboxamide anti-angiogenic agent for the treatment of prostate cancer. Prostate 66: 1768-1778

Jönsson S, Andersson G, Fex T, Fristedt T, Hedlund G, Jansson K, Abramo L, Fritzson I, Pekarski O, Runström A, Sandin H, Thuvesson I, Björk A (2004) Synthesis and biological evaluation of new 1,2dihydro-4-hydroxy-2-oxo-3-quinolinecarboxamides for treatment of autoimmune disorders: structure-activity relationship. J Med Chem 47: $2075-2088$

Kane RC, Farrell AT, Saber H, Tang S, Williams G, Jee JM, Liang C, Booth B, Chidambaram N, Morse D, Sridhara R, Garvey P, Justice R, Pazdur R (2006) Sorafenib for the treatment of advanced renal cell carcinoma. Clin Cancer Res 12: $7271-7278$

Noseworthy JH, Wolinsky JS, Lublin FD, Whitaker JN, Linde A, Gjorstrup $\mathrm{P}$, Sullivan HC (2000) Linomide in relapsing and secondary progressive MS: part I: trial design and clinical results. North American Linomide Investigators. Neurology 54: 1726-1733

Pawinski A, van Oosterom AT, de Wit R, Fosså S, Croles J, Svedberg A, Lentz MA, de Mulder PH (1997) An EORTC phase II study of the efficacy and safety of linomide in the treatment of advanced renal cell carcinoma. Eur J Cancer 33: 496-499

Petrylak DP, Tangen CM, Hussain MH, Lara Jr PN, Jones JA, Taplin ME, Burch PA, Berry D, Moinpour C, Kohli M, Benson MC, Small EJ, Raghavan D, Crawford ED (2004) Docetaxel and estramustine compared with mitoxantrone and prednisone for advanced refractory prostate cancer. N Engl J Med 351: $1513-1520$

Reese DM, Fratesi P, Corry M, Novotny W, Holmgren E, Small EJ (2001) A phase II trial of humanized anti-vascular endothelial growth factor antibody for the treatment of androgen-independent prostate cancer. Prostate J 3: $65-70$

Rock EP, Goodman V, Jiang JX, Mahjoob K, Verbois SL, Morse D, Dagher R, Justice R, Pazdur R (2007) Food and Drug Administration drug approval summary: Sunitinib malate for the treatment of gastrointestinal stromal tumor and advanced renal cell carcinoma. Oncologist 12: $107-113$

Scher HI, Halabi S, Tannock I, Morris M, Sternberg CN, Carducci MA, Eisenberger MA, Higano C, Bubley GJ, Dreicer R, Petrylak D, Kantoff P, Basch E, Kelly WK, Figg WD, Small EJ, Beer TM, Wilding G, Martin A, Hussain M (2008) Design and end points of clinical trials for patients with progressive prostate cancer and castrate levels of testosterone: 
recommendations of the Prostate Cancer Clinical Trials Working Group. J Clin Oncol 26: $1148-1159$

Smaletz O, Scher HI, Small EJ, Verbel DA, McMillan A, Regan K, Kelly WK, Kattan MW (2002) Nomogram for overall survival of patients with progressive metastatic prostate cancer after castration. J Clin Oncol 20: $3972-3982$

Steinbild S, Mross K, Frost A, Morant R, Gillessen S, Dittrich C, Strumberg D, Hochhaus A, Hanauske AR, Edler L, Burkholder I, Scheulen M (2007) A clinical phase II study with sorafenib in patients with progressive hormone- refractory prostate cancer: a study of the CESAR Central European Society for Anticancer Drug Research-EWIV. Br J Cancer 97: 1480 - 1485

Tannock IF, de Wit R, Berry WR, Horti J, Pluzanska A, Chi KN, Oudard S, Théodore C, James ND, Turesson I, Rosenthal MA, Eisenberger MA (2004) Docetaxel plus prednisone or mitoxantrone plus prednisone for advanced prostate cancer. $N$ Engl J Med 351: $1502-1512$

Weidner N, Carroll PR, Flax J, Blumenfeld W, Folkman J (1993) Tumor angiogenesis correlates with metastasis in invasive prostate carcinoma. Am J Pathol 143: 401-409 